the capitalist form of archist domination that has so disfigured our world and the lives of all those who inhabit it' (74). Therefore, this is an ideological as well as scholarly project (or perhaps not scholarly at all, if one has certain views on the relationship between scholarship and the naked pursuit of political intent). From such a perspective liberal-capitalism gets short shrift. Marshall's preface sets the tone - 'work hard now, defer joy, consume as much as you can, obey your rulers and all shall be well. This is the dead-end that liberal democracy serving capitalism has to offer' (xiv). For Clark 'totalitarianism reaches its greatest perfection in the utopia of consumption' (13). To object that a trip to the local Tesco, while far from a utopian experience in itself, seems infinitely preferable to a few years in a Soviet Gulag would of course be naive in the extreme, as the totalitarianism of consumption does not need such crude devices to enforce itself, attaining 'capture the imagination' (13) instead. The alternative, as posited in the Daodejing, sees 'a world in which humanity and nature are in harmony, in which human beings live together peacefully and cooperatively, and in which universal self-realisation is fostered' (11). This, surely, is all too easy. For the defence, capitalism - a complex and multifaceted phenomenon - has shown an astonishing ability to lift billions of people out of poverty in the past couple of hundred years, and it is technologically fecund (for all its glaring faults), but why let such complexity get in the way of a good revolutionary contribution?

This is a book for those already convinced that the relationship between anarchism and utopia is both interesting and important, and the essays by Kinna, Newman, Suissa and Gordon all make contributions to understanding the politics of this. For those not so convinced, there is nothing here to tell them why they should be.

Mathew Humphrey

School of Politics \& IR, University of Nottingham, UK

\title{
Women's rights as multicultural claims: Reconfiguring gender and diversity in political philosophy
}

\author{
Monica Mookherjee
}

Edinburgh University Press, Edinburgh, 2009, xvi + 192pp., £60.00, ISBN: 978-0748632794.

Contemporary Political Theory (2012) 11, e5-e7. doi:10.1057/cpt.2010.32 
Few issues cause more hand-wringing than the apparently competing claims of feminism and multiculturalism. It is hard to see how the logic of feminism can be curtailed by national or cultural boundaries, yet those who are persuaded by that logic are often no less moved by the claims of cultural diversity and postcolonial complaints about the export of western values. Unsurprisingly therefore the search has been on for a way of reconciling the claims of feminism and culture and it is just such a reconciliation that Monica Mookherjee offers us in this book. Her argument takes its cue from the observation that women have cultures too and that any defensible account of women's interests and women's rights must do full justice to the cultural particularity of their lives and allegiances. What we should seek is a form of gender equality that takes account of the whole of women's lives, including the cultural contexts that give them meaning. How are we to achieve that?

Mookherjee's answer mixes the universal and the particular. Although she is critical of some liberal approaches to rights, particularly the conflictual conception of rights as trumps, she herself proposes a framework of rights as the essential instrument for achieving a culturally sensitive form of gender equality. First, she proposes a 'right to mediation'. 'Mediation' here describes not third party mediation but the right of a minority group to participate in dialogue with the state so that it can articulate its own values and defend its own cultural claims. Mookherjee is concerned to ensure that women should be able to participate as equal deliberators in the exercise of that group right. That requires that they should enjoy rights that protect them from internal group coercion, including psychosocial forms of coercion, that ensure that they can develop the mental capacities necessary for equal participation, and (rather more problematically) that will counter the harmful internalisation of social norms. Second, women should enjoy the 'right to plural autonomy'. The autonomy at stake here is the 'mental ability reflectively to endorse one's life decisions' so that people do not feel alienated from the lives they live. It is 'plural' because it requires a culturally variable family of skills; Mookherjee argues that we should see cultures as resources for, rather than obstacles to, autonomy.

Mookherjee examines what these rights might require by applying them to a range of challenging cases: the practice of sati and the Shah Bano case in India, the issues of arranged and forced marriage in Britain, the educational demands of evangelical Protestants in United States who seek to insulate their children from the contaminating effects of religious and ethnic diversity, particularly the Mozert case, and the hijab issue in France. Her concerns are therefore global in reach and her culturally mediated approach to women's rights is designed for women at large rather than only those living in 'western' multicultural societies. Although her case for accommodating cultural differences is constrained by a framework of rights, her argument is rather 
more notable for the extent to which she is willing to accommodate cultural demands. Thus, she keeps on the agenda all of the cases she considers, including sati. However, her purpose is neither to endorse these cultural practices, nor to come up with right answers on specific issues; that would contradict the nature of her project. Rather it is to propose an arrangement in which women can participate on genuinely equal terms with men in determining their own future, including what they should embrace and discard in their inherited cultures.

Does Mookherjee succeed in squaring the circle? Inevitably some will find her too ready to appease the demands of conservative religious and cultural groups; others will find her too willing to subordinate the claims of culture to liberally inspired principles of freedom and equality. Mookherjee herself accepts that we sometimes have to settle for balances and compromises in a world in which 'human values cannot be perfectly reconciled', and that the choices she seeks to secure for women will not always be easy choices for them. But, for the most part, her claim is that, if we conceive the issue women's rights and cultural diversity as one of conflict, we have already set out on the wrong path. It is for women, in their full cultural particularity, to speak for themselves.

Mookherjee's book is rich in argument and empirical detail and every sentence is clearly the product of careful reflection. She packs an awful lot into each paragraph. Because she is so alive to the multitude of considerations that bear on the issues she examines, argument and counter-argument follow one another in quick succession, giving the reader little chance to relax. Her book is also impressively erudite; there seems nothing of relevance to her subject that Mookherjee has not read. Hers will not be the last word on this contentious subject, but her thoughtful, original and carefully crafted argument constitutes a major contribution to the debate and one that deserves to be widely read.

Peter Jones

Newcastle University, UK

\section{The political art of Bob Dylan}

David Boucher and Gary Browning (eds.)

Imprint Academic, Exeter, 2nd edn., 2009, 274pp., £14.99,

ISBN: 978-1845401207

Contemporary Political Theory (2012) 11, e7-e10. doi:10.1057/cpt.2010.33 